\title{
An Empirical Study on the Effect of Spices and Herbs in the Shelf Life of Dried Indian Anchovy Fish
}

\author{
*Taniya Alex ${ }^{1}$, Dr. Kannan Eagappan ${ }^{2}$ \\ ${ }^{1}$ Research Scholar Department of Food and Nutrition, Bharathiar University, Coimbatore, Tamil Nadu 641046, \\ India \\ ${ }^{2}$ Associate Professor Department of Clinical Nutrition and Dietetics, PSG College Of Arts and Science, \\ Coimbatore, India
}

\begin{abstract}
This study deals with the production of low salted and spiced dried product from anchovy fish (Stolephorus commersoni) using traditional sun drying process to achieve a reasonable shelf life at ambient tropical temperature. Proximate analysis, microbial safety, nutrient retention and product quality in terms of flavor and texture after Sun drying has been tested. This product has been subjected to storage studies, with respect to product quality and microbial status. It can be kept well for a period of 3 months.

The study on fish sample was conducted in three different ways; Sample 1 in which the fish was treated with spices and herbs like Turmeric, Salt, black Pepper and Ajwain (TSBA). Sample 2 in which the fish was treated with spices and herb like Turmeric, Salt, Red chili and Oregano (TSRO) and sample 3 is the control sample treated with only salt $(C)$. The result of the study shows that Samples 1 (TSBA) had the best chemical, microbiological and organoleptic quality when compared to Sample 2 (TSRO) and sample 3 (C). Control sample $(C)$ had very tough texture, high salt content, high moisture contents, dark discoloration. In case of sample (TSBA) and (TSRO) moisture and ash value increased which resulted in the increase of microbial load with a decrease in fat and protein during the period of 3 months of storage.

The quality changes during storage period were noted with a decrease in sensory scores for the overall acceptance. The lipid quality of the Anchovy showed gradual increase in Free Fatty Acid (FFA) which accompanied by decrease in flavor and odor scores. Microbial activity showed a marginal increase with increase in storage period. This new research reveals that the indigenous spices used, in sample 1 (TSBA) including black pepper, Turmeric and Ajwain had chemical preservative and antioxidant properties. Among the three spices, black pepper in combination with Ajwain was found to have the most effective preservation potential of sun-dried fish during storage. This study was an effective method to provide a simple, cheaper, healthier, tastier and safer method of fish preservation in developing countries like India.
\end{abstract}

Keywords: Anchovy (Stolephorous commersonii), Spices, Herbs, Sun drying, Quality, Shelf life and storage.

\section{Introduction}

Drying is considered as a traditional and widely used method of processing the fish mainly found in the tropical countries especially in the absence of refrigerated storage facilities (waterman 1976). Traditionally for the low income population dried fish represent a low cost source of high quality protein (Petrus PH 2013). According to the ministry of fisheries and Aquatic Resource Development (2013) about 10\% of the total marine fish landing is used for the production of dried fish. From the nutritional point of view fish protein has a high degree of digestibility and also considered as a rich source of lysine and Sulphur containing amino acids. Thus it can be used for complementing high carbohydrate diets especially in developing countries (Kent, 1984). According to FAO, 2008 Protein intake of about $20 \%$ is provided by the fish to about 2.6 billion people across the globe. Fishes are very rapidly susceptible to spoilage due to various intrinsic characteristics and microbial contamination from various sources (Venu Gopal et al, 1997). Various preservation methods are applied to preserve these fishes of which sun drying is one of the traditional method carried out since the pre-historic times in most of the developing countries like India. Sun dried fishes are one of the major nutrient providers to the low income people. Unsalted dried fish are heavily infested by blow flies which cause about $30 \%$ loss of product (Wood1981).

Sun drying since pre-historic is mainly applied to small and lean fishes which are easily susceptible to spoilage of one such fish is Anchovy (Stolephorous commersonii). Anchovies are small salt water fish which grow up to $20 \mathrm{~cm}$ ( 8 inches). According to Donald and beamish (2004) the fish can appear in large schools for decades and disappear the next year and reappear the year after that. Anchovies belong to the family Engraulidae. They are mainly found in the Atlantic, Indian and Pacific Ocean and there are about 144 species in 17 genera (Nina Tabitha S et al., 2012). Anchovies are considered as oily fish rich in omega-3 oils, calcium and iron (Food standard ragency 2004). These large amount poly unsaturated fatty acids present in the fish lipid makes them highly susceptible to oxidation (Huss, 1995; Boran et al, 2006). This lipid oxidation is a chain 
reaction which is a continuous supplier of free radicles which further helps to initiate the chain reaction (Mayes, 2002). This lipid oxidation in fish is the main producer of off- odor and off- flavor and reduces the nutritional value. Small fishes like anchovy, sardine etc. get easily rancid even after sun drying and smoking.

In order to overcome this drawback a study was carried out with some natural spices and herbs which not only provide good color and flavor to the product but also contain antioxidants that inhibit lipid peroxidation and other free radical-mediated processes which not only prevents the rancidity in fish but also prevented it from microbial spoilage (Takao et al., 1994). Phenolic compounds present in spices and herbs exhibit a wide range of physiological properties, including antiallergenic, anti-artherogenic, anti-inflammatory, antimicrobial, antithrombotic, cardio protective and vasodilatory effects (Balasundram et al., 2006). The study was carried out with spices and herbs in a two different combination in order to find out the effectiveness of correct combination spices and herbs in a correct proportion in enhancing shelf life of Anchovies (Stolephorus commersoni).

For the study two different combination of spices and herbs where used sample 1(TSBA) was prepared by a combination of Turmeric, salt, Black Pepper and Ajwain and sample 2 (TSRO) was prepared by a combination of Turmeric, salt, red chill, salt and oregano. After preserving the sample for three month we find that (TSBA) retained good satisfactory sensory, microbiological and biochemical properties than compared to (TSRO). This is because of the fact that spices and herb used in (TSBA) like black pepper and Ajwain is rich in glutathione peroxidase and glucose-6-phosphate dehydrogenase (Karthikeyan and Rani, 2003). Black pepper has a well-known antioxidant and radical scavenging properties which have been well documented (Gülcin, 2005). Khalaf et al. (2008) and showed that piperine can increase the absorption of selenium, vitamin B complex, betacarotene and curcumin as well as other nutrients. Similarly, Ajwain, which is commonly called as omum in Indian languages, is very useful herb which contains about 50\% thymol. This herb has a well-known antibacterial essential oil, and along with thyme can be used to enhance the immune system toward off colds and flu and other viral infections (S. N. Dwivedi et al. 2012). Chili powder is also known to have antimicrobial properties. C. annum consists of the known inhibitory substance capsaicin (Cichewicz and Thorpe., 1996). The flavor and pungent power of these peppers varies widely and so do their contents of capsaicin and its capsaicinoid analogs (Dorantes L, et al. 2000). piperine an alkaloid the major constituent of piper amides present in the skin and seed of the black pepper is responsible for the antimicrobial activity.

Oregano is generally considered as a perennial herb with small glands containing the volatile or essential oil that gives the plant its aroma and flavor (Simon et al., 1984). Many studies confirmed benefits of oregano for human health and its use for the treatment of a vast list of ailments, including respiratory tract disorders such as cough, as an oral antiseptic, in urinary tract disorders and in various dermatological infections (alleviation of itching, healing crusts, insect stings), viral infections and even good for cancer (Baricevic and Bartol, 2002).

Thus, in this research, we aim to study effectiveness of different combination of spices and herbs mixture along with salt in controlling rancidity as well as microbial growth in Anchovy (Stolephorus commersoni) and add value to the dried fish. The broad objective of the study is to determine the efficiency of spice and herbs mixture in extending the shelf-life by retarding lipid oxidation and microbial growth by providing a good organoleptic quality to the dried Indian fishes.

\section{Sample Collection}

\section{Materials and Methods}

Samples of fresh Anchovies (Stolephorus commersoni) were purchased from local market of Bangalore, Karnataka in the early hours of the day and the fishes were brought to the Laboratories, to conduct the research activities. Pure common salt, turmeric, pepper, Ajwain, Red chili powder, Oregano and Anchovies were used as raw materials for this study.

\section{Fish Preparation}

Fresh mature one kilogram Anchovies was transported to laboratory in sterile polythene to avoid any type of microbial contamination. The fish samples were washed thoroughly with potable water to remove sand and slime, and dried with disposable towel paper, measured and weighted. The average length of the fish was $7.5 \mathrm{~cm}$ while their average weight was $8 \mathrm{~g}$ (fresh weight). After cutting and cleaning the average weight of the fish was $5 \mathrm{~g}$. So we can say that almost $25 \%$ of the fish is waste. The fishes after cleaning were dipped in $10 \%$ sodium chloride solution for 15 minutes for blanching which helps to inactivate the enzymatic reaction making the fish softer in texture and also helps in removing raw flavor and blood strains. After blanching process the fishes were drained and divided into 3 batches.

At first, three samples of the raw fishes were taken for three different analyses.

\section{Sample Preparation}

Following three samples were prepared for the study: 
Sample 1- Fish with Turmeric, Salt, black Pepper and Ajwain (TSBA): Here to the cleaned fish a mixture of powdered dry salt, black pepper, turmeric and Ajwain was added gently and evenly. The total ratio of total fish and spices herb composition= Fish weight: salt: turmeric: pepper: Ajwain = 50: 3.75: 1.2: 1.2: 1 respectively. They were dried in sun for 14 hours.

Sample 2- Fish with Turmeric, Salt, Red chilli and Oregano (TSRO): Here the fish samples were treated with mixture of powdered dry salt, Turmeric, Red chili and oregano and dried in sun for 14 hours. Here the total ratio of total fish and spice herb composition= Fish weight: salt: turmeric: pepper: Ajwain = 50: 3.75: 1.2: 1.2: 1 respectively.

Sample 3- Normal Sun Dried Anchovy Fish as Control (C): Here the Anchovy fish was normally sun dried where the fish was enrolled in dry salt and the extracted salt solution was removed and dried. Thus the ratio of total composition $=$ Fish weight: salt $=3: 1$

The processed and preserved fish were kept in drier box and was netted to prevent any external contamination (mainly insects and pest).The fishes were dried for about 14 hours.

\section{Fish Storage}

The processed and preserved sun dried Anchovies were stored in Zip Lock polyethylene bags and stored at room temperature for a period of 3 months. Samples were subjected to visual observation, chemical analysis, microbiological analysis and sensory evaluations.

\section{Biochemical Analysis}

In this study the quality of the products were assessed on the basis of proximate analysis and Free fatty acid compositions of fish which includes moisture, fat, protein and ash content of dried products according to A.O.A.C. (1990) procedure. The free fatty acid value was determined by the method of Olley and Lovern (1960).

\section{Microbiological Analysis}

The Anchovy samples were analyzed for the total bacterial load using plate count agar by spread plate technique. For this test $10 \mathrm{~g}$ of the sample was mixed with $90 \mathrm{ml}$ saline water and appropriate dilutions of fish homogenate were spread on a plate count agar and incubated at $37^{\circ} \mathrm{C}$ for $24-48$ hours and the colonies were counted for total Plate count and the count was expressed as cfu/g (AOAC, 1990).

\section{Organoleptic Assessment}

The sensory evaluations of product quality were carried out by an experienced panel composed of 10 people. Coded samples along with the questionnaires were presented to the panelists. Panel members scored all factors on a 5-point Hedonic Scale as depicted on the score sheet below .The score was given on the basic quality attributes studied which include appearance, taste, texture, saltiness, rancidity (off flavor) and general acceptability (Martinsdottir et al., 2001).

Table 1: Five Hedonic Scale Rating

\begin{tabular}{|l|l|}
\hline Product Quality & Sensory Score \\
\hline Like Very Much & 5 \\
\hline Like Slightly & 4 \\
\hline Neither Like Nor Dislike & 3 \\
\hline Dislike Slightly & 2 \\
\hline Dislike Very Much & 1 \\
\hline
\end{tabular}

\section{Results and Discussion}

The comparative study was carried out on Anchovies by using two different combination of spices and herbs on the same fish to find out the most effective spices and herbs combination in enhancing the shelf life and attributing better sensory and microbiological quality to the anchovies. The study was carried on the basis of several parameters such as proximate composition, shelf life, sensory evaluation and microbiological analysis. The proximate composition of fresh anchovies used for the study had protein $15.60 \%$; fat $2.65 \%$; moisture $73.8 \%$ and ash $1.58 \%$. In this study, the sample 3 (C) was considered as the control group to study the effectiveness and preservative action of spices and herb treatment on sample (TSBA) and (TSRO).

The proximate composition (moisture, protein, fat and ash), Free fatty acid value, microbial load test and sensory evaluation of Anchovy from 1st month to 3rd month on all the three samples, the fish treated with Turmeric, Salt, black Pepper and Ajwain (TSBA), the fish treated with Turmeric, Salt, Red chilli and Oregano (TSRO) and the control dried fish sample (C) was determined. As per the study, Fat and protein are used as a 
source of energy, which decreases progressively during storage while moisture and ash content increases significantly $(\mathrm{P}<0.05)$ due to water loss.

The comparative study of the proximate composition (Fig.1), (Fig.2) \& (Fig.3) of the Anchovies (Stolephorus commersoni) cured in three different method showed that the Control Samples 3 (C) had very tough texture, high salt content, high moisture contents, dark discoloration and had very high microbial growth during drying compared to the other samples. As per organoleptic quality it was marked as dislike slightly. Whereas sample (TSBA) contained highest protein (17.69\%) and fat $(3.31 \%)$ content and lowest moisture $(12.68 \%)$ and FFA $(1.87 \%)$ content compared to sample (TSRO) which contain $(17.01 \%)$ protein, $(3.02 \%)$ fat, $(14.66 \%)$ moisture, $(3.97 \%)$ ash and $(2.20 \%)$ FFA at the end of 3rd month.

\section{TABLE 2}

\begin{tabular}{|c|c|c|c|c|c|c|c|c|c|c|c|c|c|c|c|c|c|c|}
\hline \multirow{3}{*}{\begin{tabular}{l|} 
PERIOD \\
Month
\end{tabular}} & \multicolumn{15}{|c|}{ PROXIMATE ANALYSIS } & \multirow{2}{*}{\multicolumn{3}{|c|}{$\begin{array}{l}\text { MICROBIOLOGICAL } \\
\text { ANALYSIS (cfu/g) }\end{array}$}} \\
\hline & \multicolumn{3}{|c|}{ Moisture \% } & \multicolumn{3}{|c|}{\begin{tabular}{|l|l} 
Protein $\%$ & \\
\end{tabular}} & \multicolumn{3}{|c|}{ Fat $\%$} & \multicolumn{3}{|c|}{ Ash\% } & \multicolumn{3}{|c|}{ FFA $\%$} & & & \\
\hline & $\mathrm{C}$ & TSBA & TSRO & C & TSBA & TSRO & C & TSBA & TSRO & C & TSBA & TSRO & $\mathbf{C}$ & TSBA & TSRO & $\mathbf{C}$ & TSBA & TSRO \\
\hline 1st & 21.88 & 11.67 & 12.6 & 17.44 & 17.82 & 17.62 & 3.25 & 3.57 & 3.44 & 3.22 & 3.55 & 3.62 & 1.3 & 0.1 & 1.02 & $11.3 \times 10^{3}$ & $1.83 \times 10^{3}$ & $2.32 \times 10^{3}$ \\
\hline 2nd & 23.22 & 12.01 & 13.02 & 17.32 & 17.77 & 17.46 & 3.01 & 3.44 & 3.21 & 3.41 & 3.62 & 3.66 & 2.5 & 1.11 & 1.88 & $56.6 \times 10^{3}$ & $2.36 \times 10^{3}$ & $3.67 \times 10^{3}$ \\
\hline 3rd & 24.77 & 12.68 & 14.66 & 17.09 & 17.69 & 17.23 & 2.89 & 3.39 & 3.02 & 3.66 & 3.68 & 3.77 & 4.3 & 1.73 & 2.02 & $11.2 \times 10^{4}$ & $3.1 \times 10^{3}$ & $5.6 \times 10^{3}$ \\
\hline
\end{tabular}

The results of Proximate, FFA and microbiological evaluation of all the three samples (C), (TSBA) and (TSRO) till the end of 3rd month of storage at room temperature are shown in Table 2

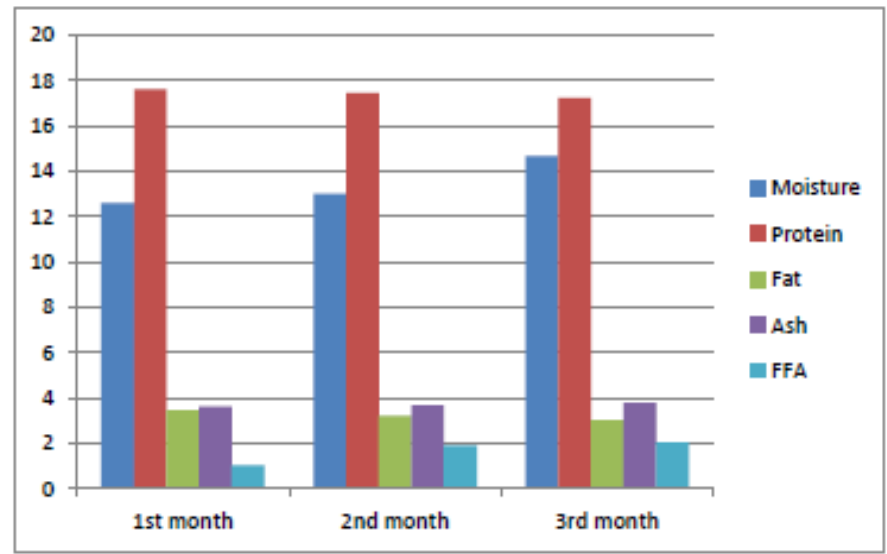

Fig. 1: Changes in Proximate Composition of Sun dried Anchovy treated as control sample (C)

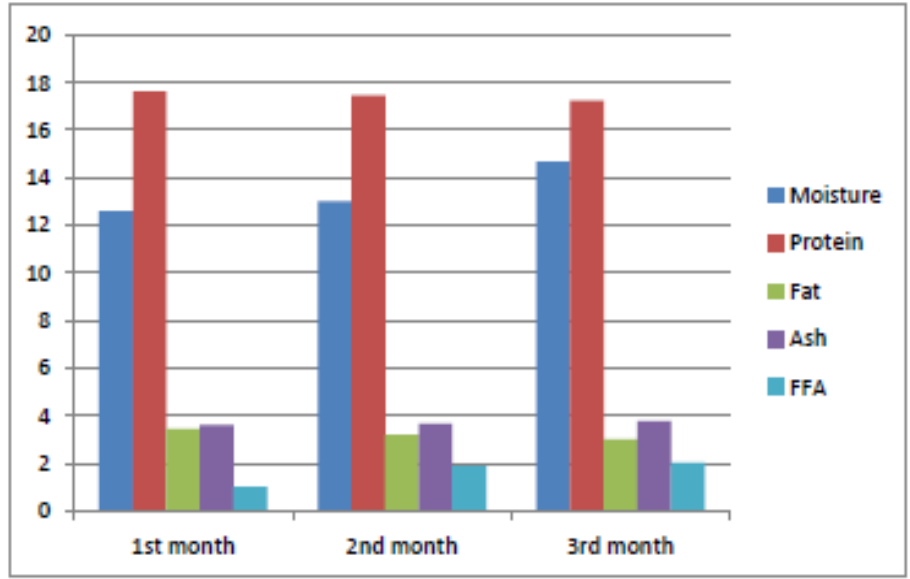

Fig: 2 Changes in Proximate Composition of Sun dried Anchovy as sample (TSBA) 


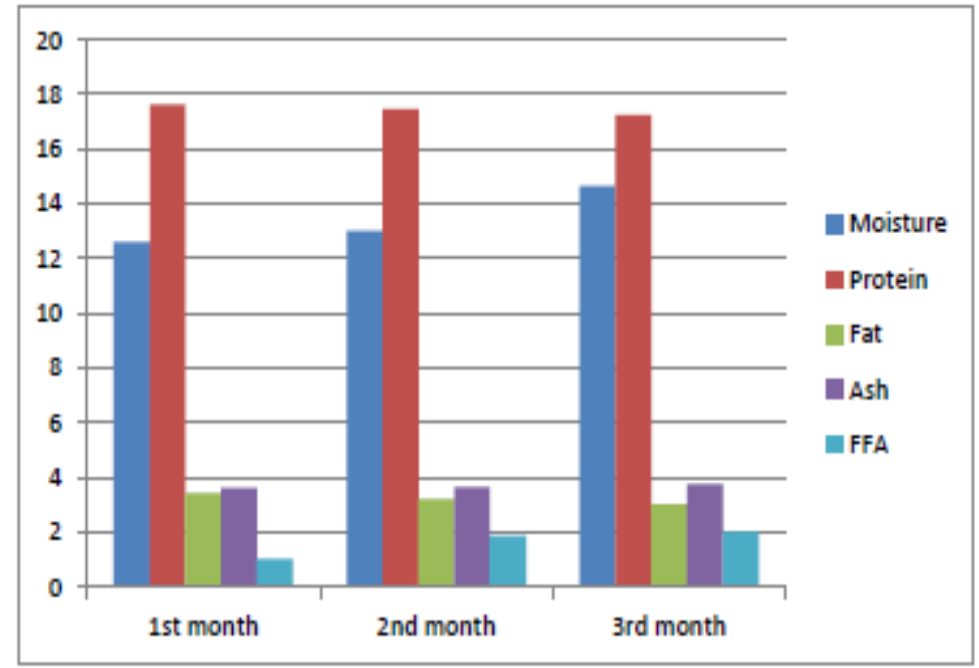

Fig: 3. Changes in Proximate Composition of Sun dried Anchovy as sample (TSRO)

\section{Proximate Composition}

The moisture content is one of the indicators which will determine the rate at which deterioration in fish occurred resulting in early decomposition. The sample (TSBA) had lowest moisture content of the (12.68\%) in case of (TSBA) compared to that of (TSRO) and (C) which had (14.66\%) and (24.77\%) respectively. This indicates that other than the common spice like Turmeric and salt used in both the samples, in (TSBA) sample which contained black pepper and ajwain had more resistant to the enzymatic and microbial activities and these qualities may have lengthened their shelf-life. Drying when combined with both salt and spices herb combination had duel effects which result in lowering of the water activity (aw) level and a specific inhibitory effect on the growth of some species of microorganisms. The main cause of decrease in moisture was due to osmotic migration of salt and spices and herb used in (TSBA) had much more capacity to migrate inside the fish and which result in oozing water out of the fish (Horner, W.F.A. 1997). This decrease in moisture leads to increase in spice content and consequently extend shelf life of the product (Lopez, A. 1987) and (Itou, K et al., 2000).

The comparative study of the nutrient composition (Table 2) of the Anchovy fish cured by three different methods showed that the (TSBA) contained the highest protein $(17.69 \%)$ fat $(3.39 \%)$ content with lower FFA (1.87\%) content as compared to (TSRO) and (C). The dried fish sample generally contains more nutrients than fresh fish (khuda M.A.A 1962). In storage condition, normally the protein content starts to decrease significantly with the time because water soluble protein diffused out to the surrounding for exosmosis (Hassan, M.N. et al., 2013) whereas here the spices and herb treatment used in sample (TSBA) were very effective in preventing the degradation of protein. This gradual degradation of initial crude protein lead to

There was a steady increase in bacterial count during the storage period in all the three treatments. However, sample (TSBA) showed lower microbial count of $3.1 \times 103 \mathrm{cfu} / \mathrm{g}$ compared to (TSRO) having a $5.6 \times 103 \mathrm{cfu} / \mathrm{g}$ and $(\mathrm{C})$ having $1.12 \times 105 \mathrm{cfu} / \mathrm{g}$ of TPC by the end of $3 \mathrm{rd}$ month of storage at room temperature. The combination of spices and herb treatment with solar drying in (TSBA) sample resulted in the decrease of microbial levels because this spices and herbs like black pepper and ajwain used in (TSBA) had more significant antimicrobial effect against different bacteria than sample (TSRO) which prevents the growth of microorganisms. According to (Abhishek S. 2011) spices and herbs have a significant antimicrobial effect, against various microorganisms and impart various nutritive health benefits to the body. whereas in case of $(\mathrm{C})$ sample due to the absence of spices and herbs lead to lipid oxidation in the fish and resulted in the rancidity and off flavor. 


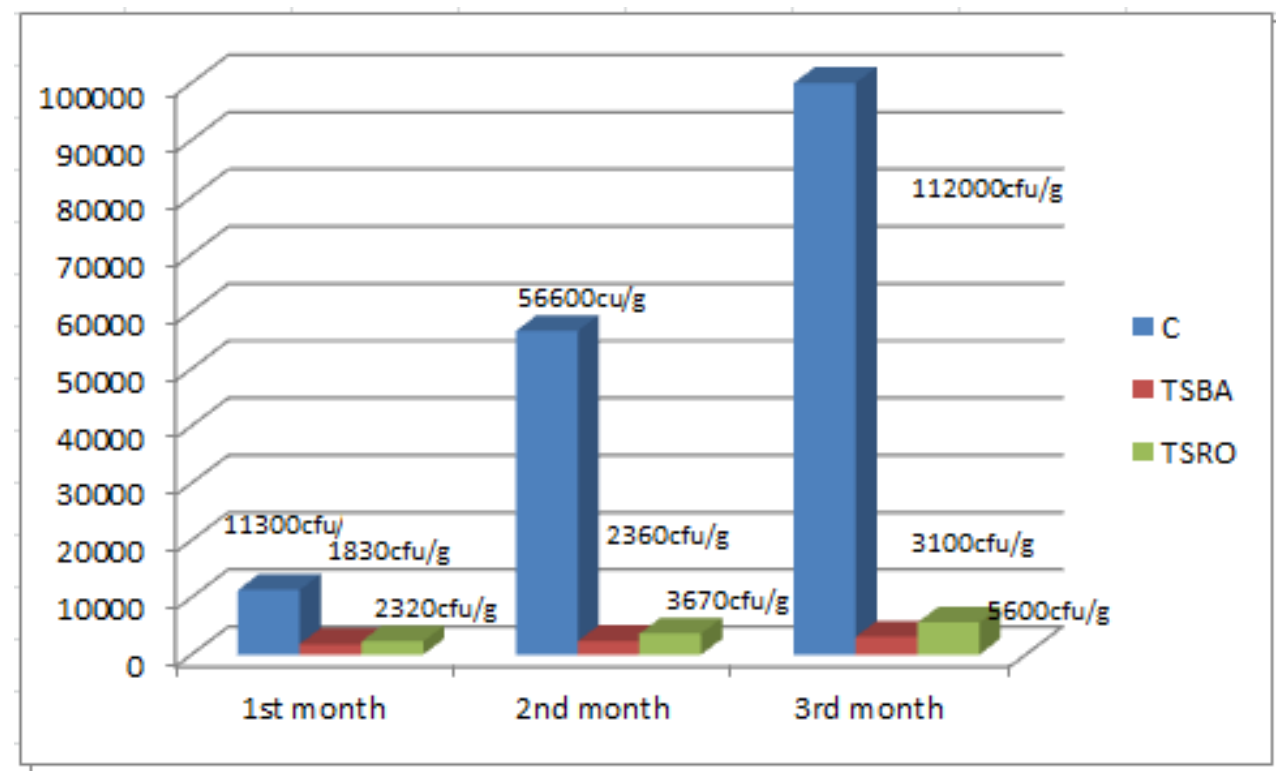

Fig 4: Shows variation in TPC values at specific intervals of the time related to the extension of the shelflife of sample (C), (TSBA) and (TSRO).

\section{Organoleptic Assessment}

The sensory evaluation was carried out by 10 panel members on the basis of 5 Hedonic Scale Rating on the basis of 5 attributes (Appearance, texture, taste, saltiness and rancidity) on their acceptability. The mean score by the panelist for the samples (TSBA), (TSRO) and (c) during 3 month storage period showed that (TSBA) samples received highest panel scores compared to (TSRO) and (C) samples with regards to appearance, rancidity, saltiness, texture and general acceptability. Sample (TSBA) had longer shelf-life than that of the other two samples. This may be due to the spicy taste and appropriate low salt taste of sample (TSBA) whereas the pungent taste of red chili and oregano of (TSRO) lead to lower consumer preference. The (TSRO) remained acceptable (sensory score 4.) for 3 months of storage. Similarly Control sample (C) had very tough texture, high salt content, high moisture contents, dark discoloration which was the main cause of dislike by the panel members.

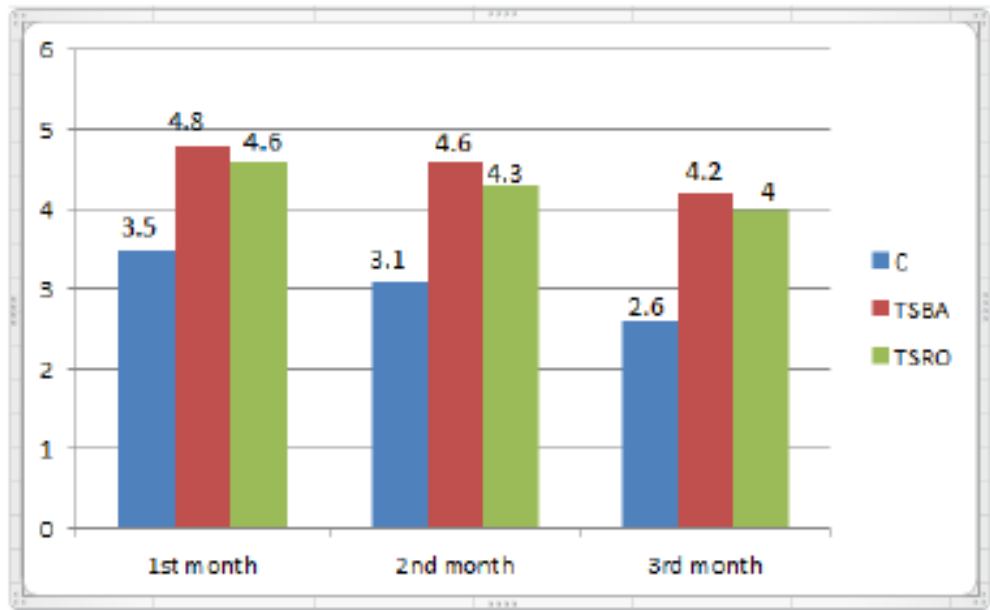

Fig 5: Sensory score values of the sample (C), (TSBA) and (TSRO) pinpointing the level of acceptability by the panel judges.

\section{Conclusion}

The present research revealed that the application of salt, pepper, turmeric and Ajwain treated with Anchovy (TSBA) sample was acceptable and had higher shelf life than the other two samples Sample (TSRO) and control sample (C). The spices and herbs used for this study were more effective in preserving fish products 
due to their nutrient properties, higher sensory score, and resistance against bacterial and enzymatic activity. Due to these properties sample TSBA had long shelf life when compared with other samples.

The spices and herbs used to prepare the sample (TSBA) had high active phenolic antioxidant property which inhibited the free-radical mediated damages like lipid oxidation thus preventing oxidative rancidity (Khatun et al. 2006). This study also revealed the anti-microbial activity of the spices and herbs when added in a correct proportion on Anchovy. The ratio used in this study was Fish weight: salt: turmeric: pepper: Ajwain = 50: 3.75: 1.2: 1.2: 1 respectively. This helped to increase protection against insects, pests, bacteria, fungus and other pathogens acting as a natural preservative and a taste enhancing ingredient.

Generally in salting methods salt is used to remove water from fish body and makes the fish to dry whereas spices and herbs helped to remove water from fish body and also favorably adds some nutrients and bioactive compounds which prevented the growth of micro-organisms. So, this process can be recommended as a preservation technique in large scale dry fish production.

\section{Reference}

[1]. Waterman, J.J. (1976). The production of dried fish. FAO fish report (F42), FAO, Rome.

[2]. Petrus PH, Suprayitno E, Physicochemical characteristics, sensory acceptability and microbial quality of WadiBetok a traditional fermented fish from South Kalimantan, Indonesia. International Food Research Journal; 2013.20(2), pp933-939.

[3]. Ministry of Fisheries and Aquatic Resource Development, (2013a) Fisheries statistics (2013). Ministry of Fisheries and Aquatic Resources.

[4]. Kent, G. (1984). National fisheries policy of Thailand, FAO Fisheries circular No 777, FAO, Rome, Italy.

[5]. CMFRI, Annual Report, 2009-2010,pp 29

[6]. Nina Tabitha S,Gunalan B. Adv Appl Sci Res 2012, 3, 3855 "What's an oily fish?".Food Standards Agency2004-06-24.

[7]. Donald NJ, Beamish RJ. Synchrony of marine fish catches and climate and ocean regime shifts in the North Pacific Ocean. Marine and Coastal Fisheries: Dynamics, Management, and Ecosystem Science.2009;1:155-168. doi: 10.1577/C08-001.1. [Cross Ref]

[8]. Huss, H. H. 1995. Quality and Quality Changes in Fresh Fish. FAO FisheriesTechnical Paper 348, Food and Agriculture Organization of the United Nations, Rome.

[9]. Boran, G., Karacam, H. and Boran, M. 2006. Changes in the Quality of Fish Oils Due to Storage Temperature and Time. Food Chem., 98: 693-698.

[10]. Mayes, P. A. 2002. Lipids of Physiologic Significance. In: "Harper's Biochemistry", (Eds.): Murry, R. K., Granner, D. K., Mayes, P. A. and Rodwell, V. W.. 25th Edition, McGraw-Hill Education (Asia), New Delhi, PP. 160-171.

[11]. WOOD, C. D. 1981. The prevention of losses in cured fish. FAO Fish. Techn. Pap. 219: 87.

[12]. S. N. Dwivedi, R. P. Mishra and Sangeeta Alava May, 2012, Phytochemistry, Pharmacological studies and Traditional benefits of Trachyspermumammi (Linn.) Sprague, INTERNATIONAL JOURNAL OF PHARMACY \& LIFE SCIENCES, ISSN: 0976-7126.

[13]. Cichewicz, R. H., \& Thorpe, P. A., (1996). The antimicrobial properties of Chile peppers (Capsicum species) and their uses in Mayan medicine. Journal of Ethnopharmacol. 52:61-70.

[14]. Dorantes L, Colmenero R, Hernandez H, Mota L, Jaramillo ME, et al. (2000) Inhibition of growth of some foodborne pathogenic bacteria by Capsicum annum extracts. International Journal of Food Microbiology 57: 125-128.

[15]. Baricevic, D. and Bartol, T. (2002). The biological/pharmacological activity of the oregano genus. In Kintzios, S. (ed.) Medical and Aromatic Plants- Industrial profilesOregano: The Genera Origanum and Lippa, London, Taylor\& Francis, pp 177-214. Simon, J. E., Chadwick, A. F. and Cracker, L. E. (1984). Herbs: An Indexed Bibliography 1971-1980. The Scientific Literature on selected Herbs and Aromatic Plants of the Temperate Zone, Hamden, CT, Archon Books, pp770.

[16]. Simon, J. E., Chadwick, A. F. and Cracker, L. E. (1984). Herbs: An Indexed Bibliography 1971-1980. The Scientific Literature on selected Herbs and Aromatic Plants of the Temperate Zone, Hamden, CT, Archon Books, pp770.

[17]. AOAC, Official method of analysis. Association of Official Agricultural Chemists W. Horwitz (Editor) 12th ED. Washington. 1990 .

[18]. Olley T, Lovern JA. Phospholipid hydrolysis of cod flesh stored at various temperatures. J Sci Food Agric. 1960;11(1):664-652.

[19]. Martinsdottir, E., Sveinsdottir, K., Luten, J., Schelvis-Smit, R. and Hyldig, G. (2001). Sensory Evaluation of Fish Freshness. Reference manual for the fish sector. QIM-Eurofish. 50pp

[20]. Sokal R. R. and Rohlf F. J., 1962. Introduction to biostatistics. New York: W. H. Freeman and Company, 1987, 363pp.

[21]. Horner, W.F.A. 1997. Preservation of fish by curing (drying, salting and smoking). In Fish Processing Technology. Blackie Academic \& Professionals, New York .31-71 pp

[22]. Lopez, A. 1987. A complete course in canning Book: II and III, 12th Ed. The canning Trade Inc. Baltimore USA.

[23]. Itou, K. and Akahane, Y. 2000. Changes in proximate composition and extractive components of rice- bran- fermented mackerel during processing.1051-1058

[24]. Khuda, M.A.A. 1962. Chemical composition and quality of traditionally processed fish, Pak. J. Sci. Ind. Res., 5(2): 70-73

[25]. Hassan, M.N. Rahman, M. Hossain, M.M. Nowsad, A.A.K.M. and Hossain, M.B. Post-Harvest Loss and Shelf Life of Traditionally Smoked Shrimp Products Produced in Bangladesh. World J. of Fish and Marine Sci. 5 (1): 14-19. 2013.

[26]. Eyo, A. A... Fish processing technology in the tropics, University of Ilorin Press. 403pp 2001.

[27]. FAO, Present and future markets for fish and fish products from small-scale fisheries - case studies from Asia, Africa and Latin America. 2008, Rome: FAO Fisheries Circular. No. 1033. p. 87.

[28]. Abhishek S., 2011. Antimicrobial and phytochemical analysis of common Indian spices against food borne pathogens.Adv Bio Tech., (5): 22-27

[29]. Khatun, M., Eguchi, S., Yamaguchi, T.,Takamura, H. and Matoba, T. 2006. Effect of Thermal Treatment on Radical scavenging Activity of Some Spices. FoodSci. Technol. Res., 12: 178-185.

[30]. Venugopal, V., S.N. Doke and P. Thomas, 1997. Thermostable water dispersion of shark meat and its application to prepare protein powder. J. Aquatic Food Prod. Technol., 6: 53-67.

[31]. Takao T, Kitatani F, Watanabe N, Yagi A, Sakata K (1994). A simple screening method for antioxidants and isolation of several antioxidants produced by marine bacteria from fish and shellfish. Bioscience. Biotechnol. Biochem. 58: 1780-1783.

[32]. Balasundram, N., K. Sundram and S. Samman, 2006. Phenolic compounds in plants and agri-industrial by-products: Antioxidant activity, occurrence and potential uses. Food Chem., 99: 191-203. 
[33]. Karthikeyan J, Rani P. Enzymatic and non-enzymatic antioxidants in selected Piper species. Indian J Exp Biol. 2003;41:135-140

[34]. Gülcin I. The antioxidant and radical scavenging activities of black pepper (Piper nigrum) seeds. Int J Food SciNutr. 2005;56:491499 